\title{
Description of larval and juvenile stages of the grapsid crab Helice leachi Hess (Brachyura: Grapsidae) reared under laboratory conditions
}

\author{
Md. Younus Mia and Shigemitsu Shokita
}

\begin{abstract}
The larval development of Helice leachi Hess, 1865, consists of five zoeal stages and one megalopal stage. The morphology of all larval stages and the first crab stage is described and illustrated. The morphological characters of the larvae of $\mathrm{H}$. leachi are compared with those of $H$. japonica and $H$. tridens. The zoeae of $\mathrm{H}$. leachi are unique among the species of Helice in lacking a lateral carapace spine.
\end{abstract}

\section{Introduction}

Helice leachi Hess, 1865 is a mediumsized grapsid crab inhabiting mud fringes of tropical or subtropical mangrove swamps, upper tidal zones near estuaries and inland seas in the Indo-West Pacific from Japan, Taiwan, Korea, Indonesia, Australia, Madagascar, East coast of Africa, Caroline Islands, New Caledonia, Moluccas and Lombok (Sakai, 1976; Dai \& Yang , 1991).

Complete larval development in the genus Helice is known only for $H$. japonica Sakai \& Yatsuzuka and $H$. tridens de Haan [under the names of $H$. tridens wuana Rathbun and $H$.tridens tridens de Haan, respectively] (Baba \& Moriyama, 1972). The incomplete larval morphology of $H$. leachi was made known by Baba et al. (1984) who described the first and second zoeae. This paper provides a morphological description of all the larval stages of $H$. leachi, including a megalopa, and the first crab, obtained under laboratory conditions.
Materials and Methods

Ovigerous females of Helice leachi collected from the mangrove area of the Oura River, Okinawa Island, southern Japan, were brought to the laboratory and reared in a plastic container filled with $20 \%$ seawater with moderate aeration. The hatched larvae were reared in different containers under the same conditions. The water was aerated and renewed daily. The containers were left at room temperature, approximately $23.6^{\circ} \mathrm{C}$, ranging from $22.5^{\circ} \mathrm{C}$ to $25.8^{\circ} \mathrm{C}$. Newly hatched Artemia nauplii were fed to the larvae daily. Minced meat of the shortnecked clam Ruditapes philippinarum (Adam \& Reeve) was fed to the megalopa and the first crab.

Several larvae of each stage were preserved in a $50 \%$ ethylene glycol solution and dissected under a binocular stereomicroscope. Drawings and measurements were made with the aid of a profile projector and a dissecting microscope. At least ten specimens of each stage were measured. Measurements taken for the zoeal stages include: distance between the tips of dorsal and rostral spines (TT), and carapace length (CL) from the base of the rostral spine to the posterior margin of the carapace. For the megalopa: carapace width $(\mathrm{CW})$ at the maximum distance across the carapace, and (CL) as above.

\section{Results}

The larvae of Helice leachi hatched out early in the morning on 14th May 1995 


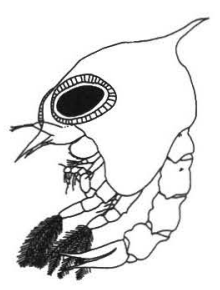

A

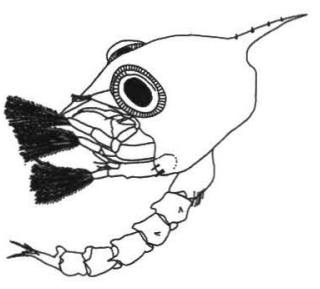

D

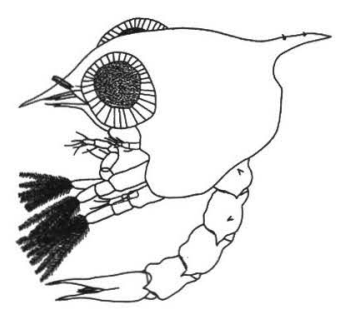

B

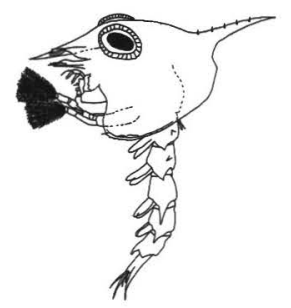

$\mathrm{E}$

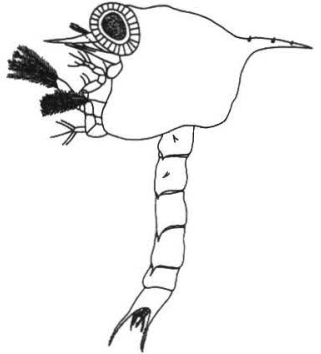

C

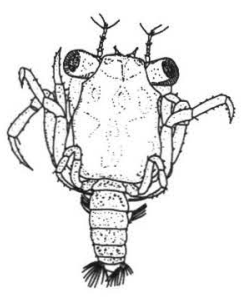

F

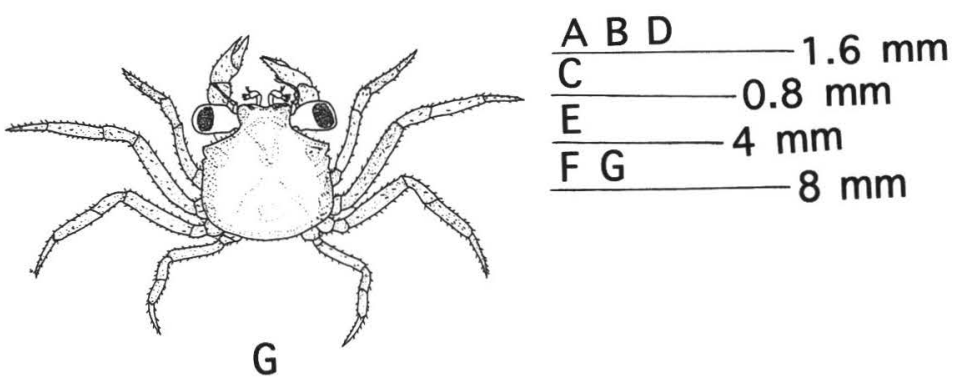

Fig. 1. Helice leachi Hess. A-E, zoea I-V; F, megalopa; G, first crab.

and passed through five zoeal stages and one megalopal stage in 38 days before moulting into the first crab stage. The major characteristics of the larvae and the first crab stage are described below.

\section{First zoEA}

Size: TT, $0.86 \mathrm{~mm}$; CL, $0.54 \mathrm{~mm}$.

Carapace (Fig. 1A): Smooth, inflated, no lateral spine. Rostral spine relatively short, nearly as long as dorsal spine. Eyes sessile.
Antennule (Fig. 2A): Conical, with 3 terminal aesthetascs and 1 seta.

Antenna (Fig. 3A): Spinous process well-developed, bearing 2 rows of denticles; exopod with short median setae, rod like, tapering, slightly shorter than spinous process.

Mandible (Fig. 4A): Incisor and molar processes differentiated.

Maxillule (Fig. 5A): Endopod 2-segmented, with 4 terminal hairy spines plus 1 subterminal hairy spine and 1 seta on 


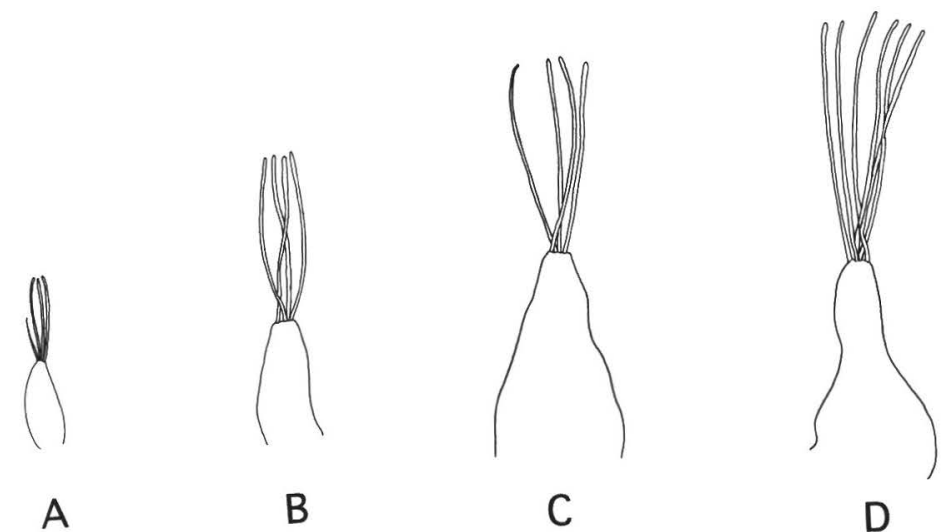

$\underline{A-G \quad 0.2 \mathrm{~mm}}$

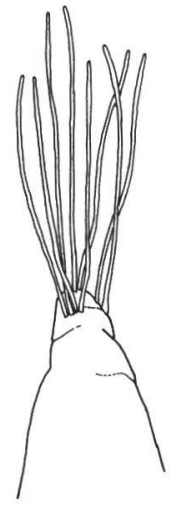

$E$

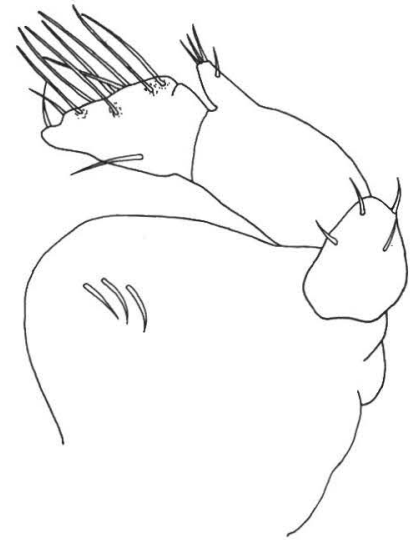

$\mathrm{F}$

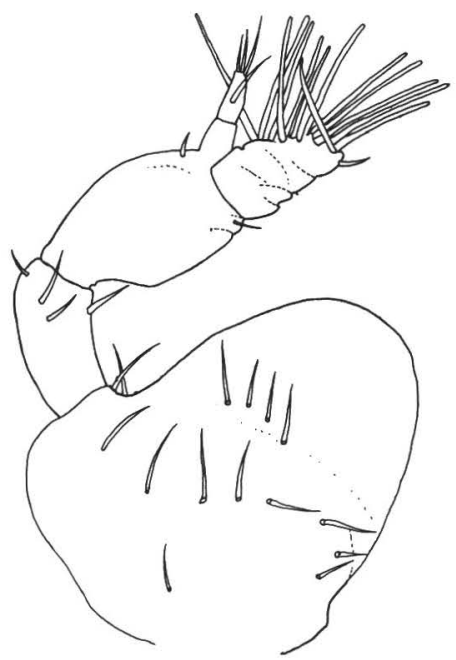

G

Fig. 2. Helice leachi Hess. Antennules: A-E, zoea I-V; F, megalopa; G, first crab.

inner side of basal segment. Basal and coxal endites with 5 and 4 hairy spines, respectively.

Maxilla (Fig. 6A): Endopod unsegmented, bearing 4 hairy setae; basal endite bilobed, with 3-4 hairy setae, coxal endite with 5 hairy setae; scaphognathite with 4 plumose setae on distal margin, apical process tapering, fringed with fine setae in distal half.
Maxilliped 1 (Fig. 7A): Basis with 10 medial setae; endopod 5-segmented, with 2, 2, 1, 2, 5 setae. Exopod 2-segmented; distal segment with 4 plumose natatory setae.

Maxilliped 2 (Fig. 9A): Basis with 4 medial setae; endopod 3-segmented, with 0, 1, 6 setae. Exopod 2-segmented; distal segment with 4 plumose natatory setae. Abdomen (Fig. 12A): Five somites plus 

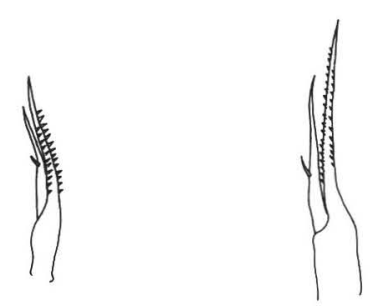

A

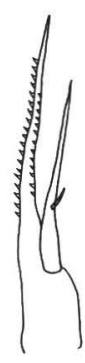

C

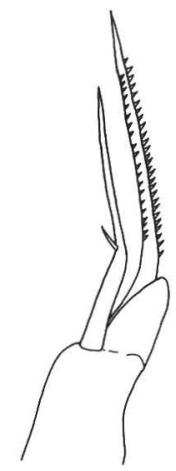

D

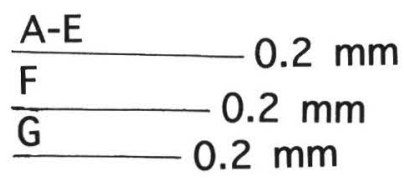

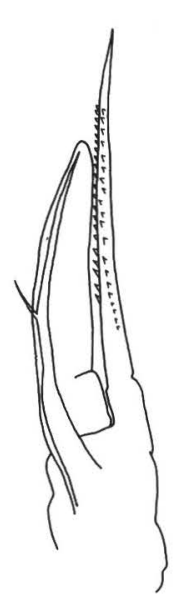

E

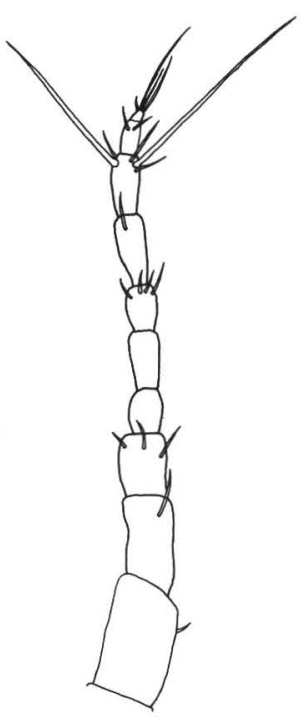

$\mathrm{F}$

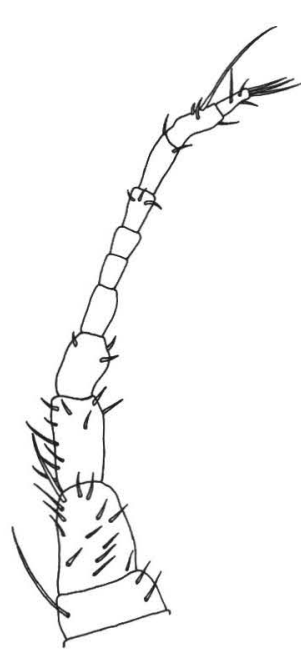

G

Fig. 3. Helice leachi Hess. Antennae: A-E, zoea I-V; F, megalopa; G, first crab. 


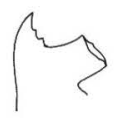

A

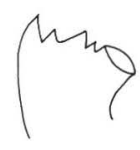

B

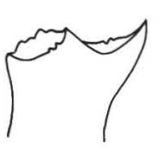

C

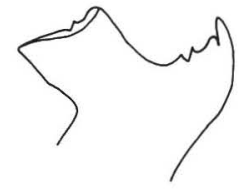

D

\section{A-G $0.2 \mathrm{~mm}$}

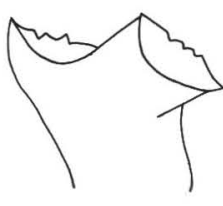

E

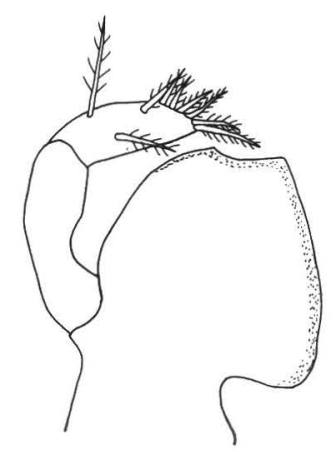

$\mathbf{F}$

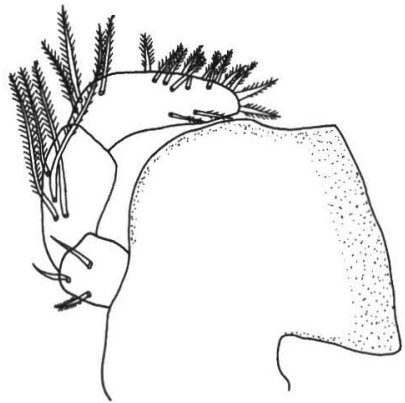

G

Fig. 4. Helice leachi Hess. Mandibles: A-E, zoea I-V; F, megalopa; G, first crab.

telson. Somites 2 and 3 with pairs of spines on dorsolateral margins, former directed anteriorly and latter posteriorly; posterolateral margins on somites 4 and 5 produced moderately. Forks of telson moderately widened, slightly longer than basal portion, bearing minute hairs on inner and outer margins; posterior margin with 3 pairs of setae.

\section{SECOND ZOEA}

Size: TT, $1.11 \mathrm{~mm}$; CL, $0.67 \mathrm{~mm}$.

Carapace (Fig. $1 \mathrm{~B}$ ): Increased in size. Dorsal spine with 2 simple setae. Eyes movable.

Antennule (Fig. 2B): Four equal-sized terminal aesthetascs.

Antenna (Fig. 3B): Spinous process and exopod relatively longe, more than twice as long as remaining basal segment. Mandible (Fig. 4B): Incisor process with 4 teeth; molar process subcylindrical.

Maxillule (Fig. 5B): Basal endite with 7 hairy spines and coxal endite with 5 ; basal segment with 1 plumose seta.

Maxilla (Fig. 6B): Basal endite bilobed, with $3+6$ setae, coxal endite with 6 setae; scaphognathite with 5 plumose setae on distal margin, apical process flattened, distally rounded, with 3 plumose setae.

Maxilliped 1 (Fig. 7B): Endopod and basis as in first zoea. Exopod with 6 plumose natatory setae.

Maxilliped 2 (Fig. 9B): Endopod and basis unchanged. Exopod with 6 plumose natatory setae. 


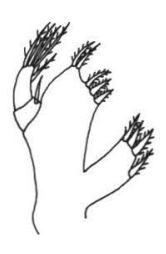

A

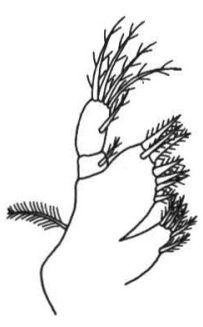

B

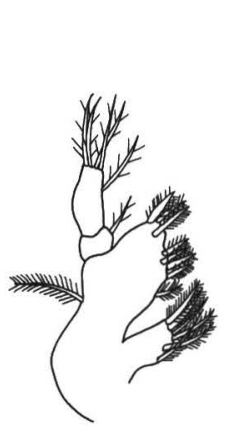

C

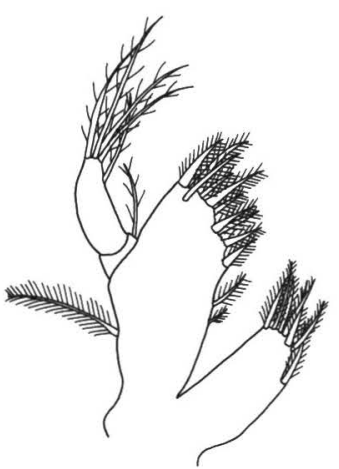

D

\section{A-G} $0.2 \mathrm{~mm}$

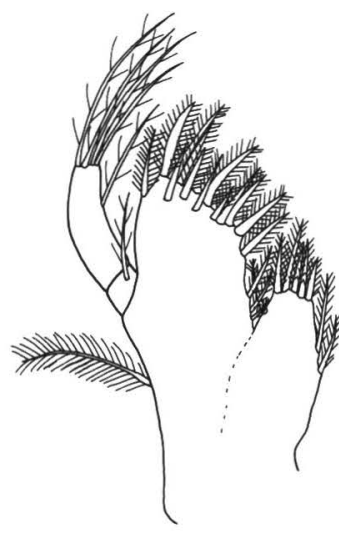

$E$

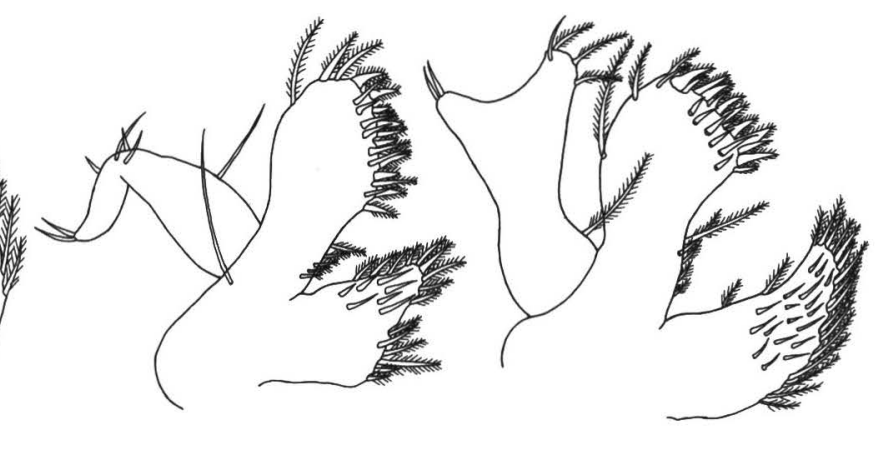

F
G

Fig. 5. Helice leachi Hess. Maxillules: A-E, zoea I-V; F, megalopa; G, first crab.

Abdomen (Fig. 12B): Somite 1 with a short seta on dorsal surface. Telson increased only in size.

\section{THIRD ZOEA}

Size : TT, $1.43 \mathrm{~mm}$; CL, $0.83 \mathrm{~mm}$.

Carapace (Fig. 1C): Increased in size. Dorsal spine with 3 simple setae.

Antennule (Fig. 2C): Base inflated; number of aesthetascs as in second zoea.

Antenna (Fig. 3C): Elongated and increased in size.

Mandible (Fig. 4C): Incisor process with teeth on one side and unarmed on opposite side; molar process denticulated.
Maxillule (Fig. 5C) : Basal endite with 8 hairy spines, coxal endite with 6 hairy spines.

Maxilla (Fig. 6C): Basal endite with $4+6$ setae, coxal endite with 6 setae; scaphognathite with 10 plumose setae on distal margin and and 3 on apical process.

Maxilliped 1 ( Fig. 7C): Exopod with 8 plumose natatory setae. Other parts unchanged.

Maxilliped 2 (Fig. 9C): Exopod with 8 plumose natatory setae. Other parts unchanged.

Abdomen (Fig. 12C): Six somites; somite 1 with 3 setae on dorsal surface. 


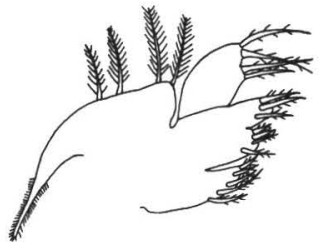

A

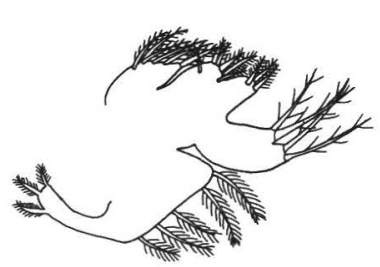

B

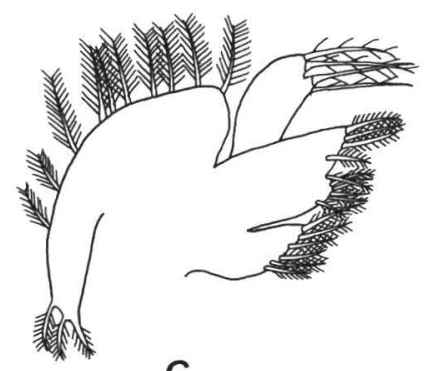

C

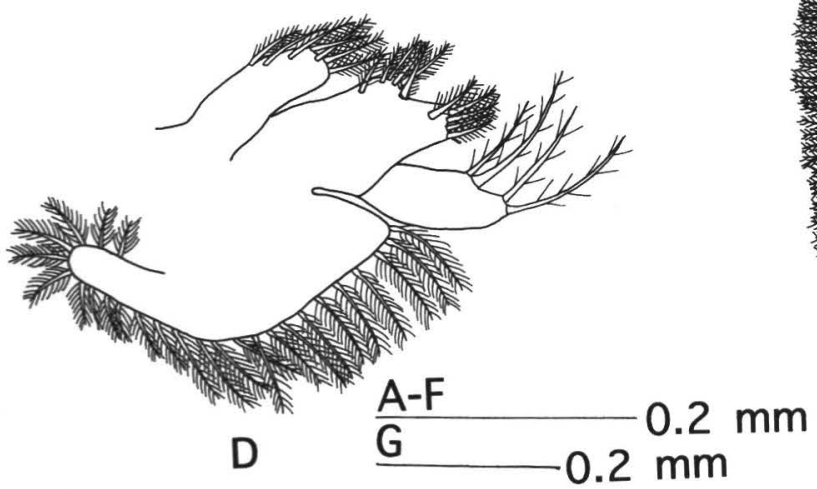

E
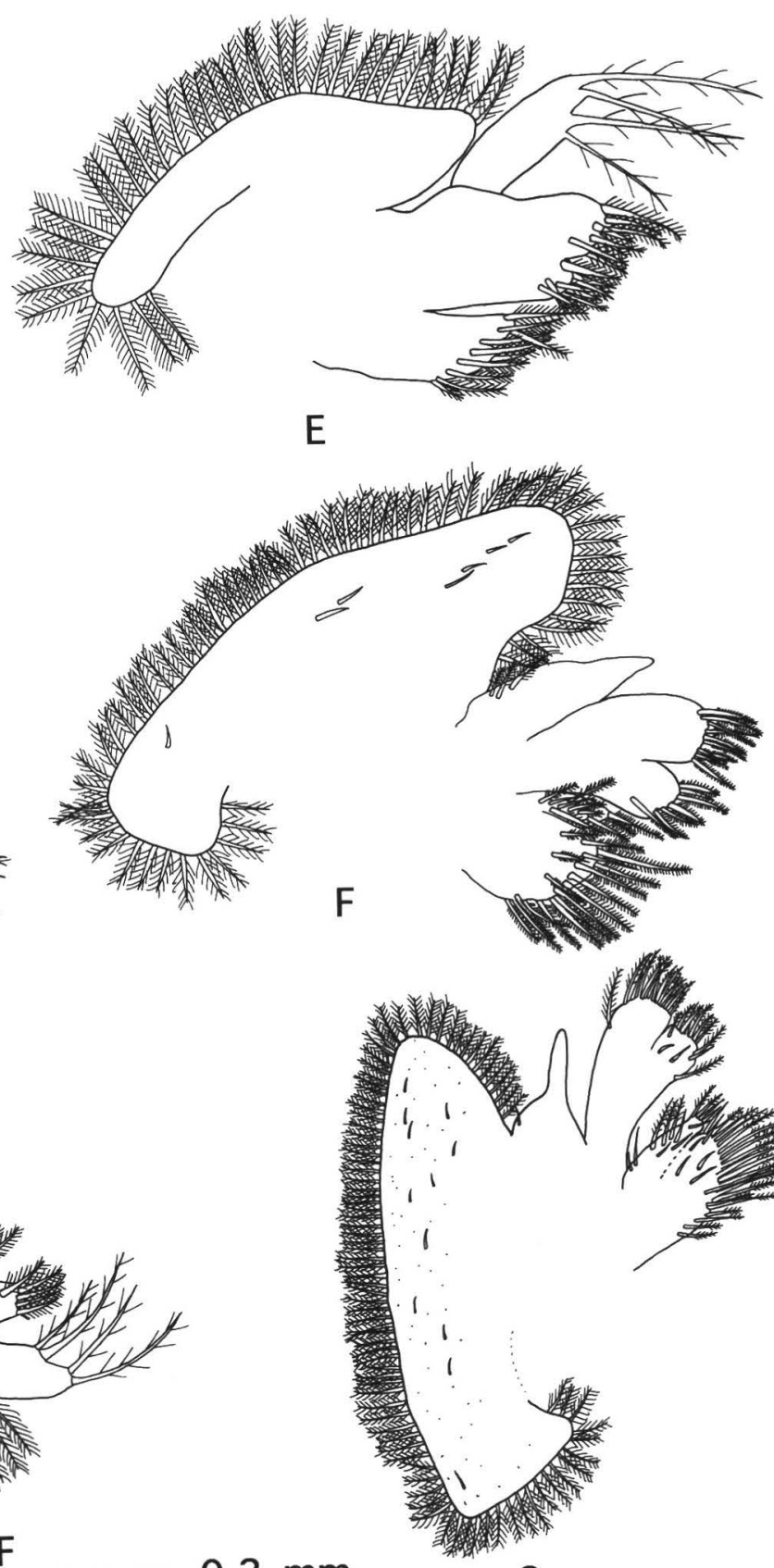

G

Fig. 6. Helice leachi Hess. Maxillae: A-E, zoea I-V; F, megalopa; G, first crab. 

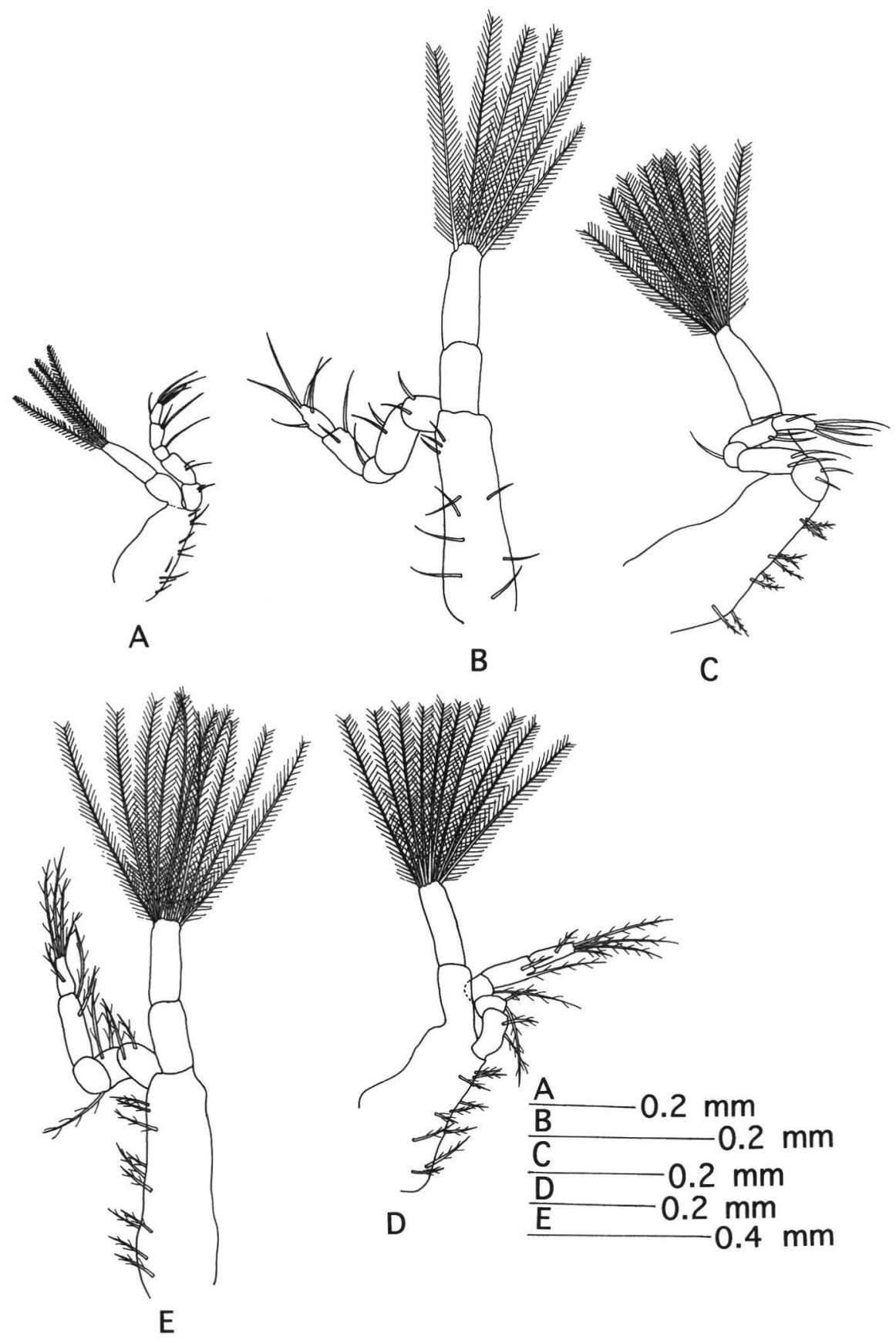

Fig. 7. Helice leachi Hess. Maxillipeds 1: A-E, zoea I-V. 


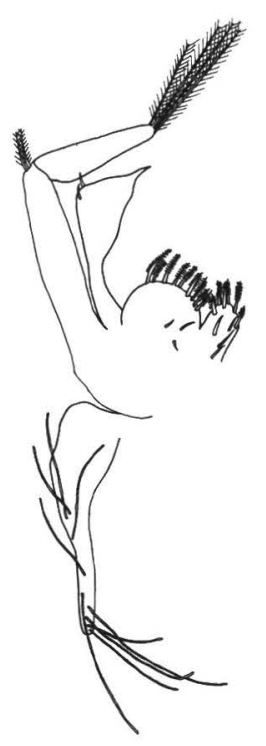

A

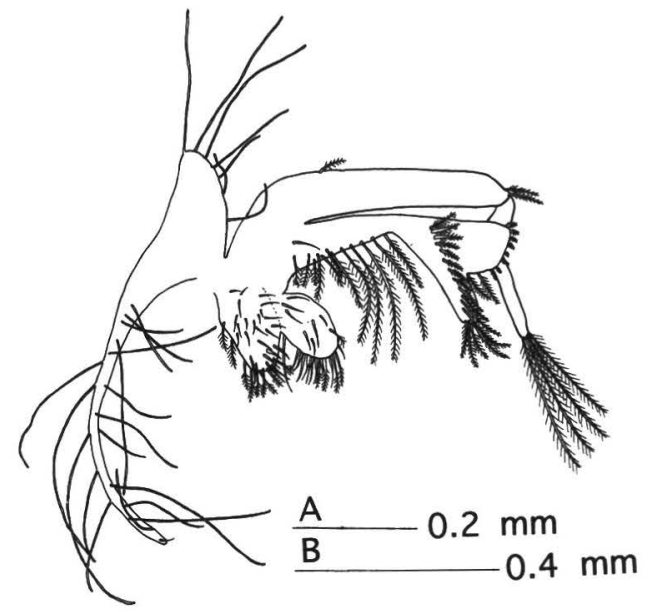

B

Fig. 8. Helice leachi Hess. Maxillipeds 1: A, megalopa; B, first crab.

Fork longer than basal portion of telson, posterior margin with 4 pairs of setae.

\section{Fourth ZOEA}

Size: TT, $1.84 \mathrm{~mm}$; CL, $1.05 \mathrm{~mm}$.

Carapace (Fig. 1D): Increased in size. Dorsal spine with 4 simple setae; 2 short spines on posterolateral margin.

Antennule (Fig. 2D): Six terminal aesthetascs.

Antenna (Fig. 3D): Base inflated; endopod bud appeared.

Mandible (Fig. 4D): Incisor process with 3 teeth on one side; masticatory surface of molar process gradually flattened.

Maxillule (Fig. 5D): Basal endite with 12 hairy spines, coxal endite with 7 hairy spines.

Maxilla (Fig. 6D): Basal endite with $5+6$ setae, coxal endite with 7 setae; scaphognathite with 26 plumose setae.

Maxilliped 1 (Fig. 7D): Endopod and basis unchanged. Exopod with 10 plumose natatory setae.

Maxilliped 2 (Fig. 9D): Exopod with 10 plumose natatory setae. Other parts un- changed.

Pereiopods: Present as small buds.

Abdomen (Fig. 12D \& E): Somites 2-5 with posteroventral pleopod buds, somote 1 with 5 setae on dorsal surface. Telson as in third zoea.

\section{Fifth zoEA}

Size: TT, $2.45 \mathrm{~mm}$; CL, $1.30 \mathrm{~mm}$.

Carapace (Fig. 1E): Dorsal spine with 5 simple setae. Posterolateral margin dentated with 8 small spines.

Antennule ( Fig. 2E): Two terminal and 6 subterminal aesthetascs.

Antenna (Fig. 3E): Endopod well-developed, shorter than spinous process.

Mandible (Fig. 4E): Incisor process with teeth on one side; masticatory surface of molar process flattened.

Maxillule (Fig. 5E): Basal endite with 16 hairy spines, coxal endite with 8 hairy spines.

Maxilla (Fig. 6E): Basal endite with $8+8$ setae, coxal endite with 10 setae; scaphognathite with 35 setae.

Maxilliped 1 (Fig. 7E): Exopod with 11 

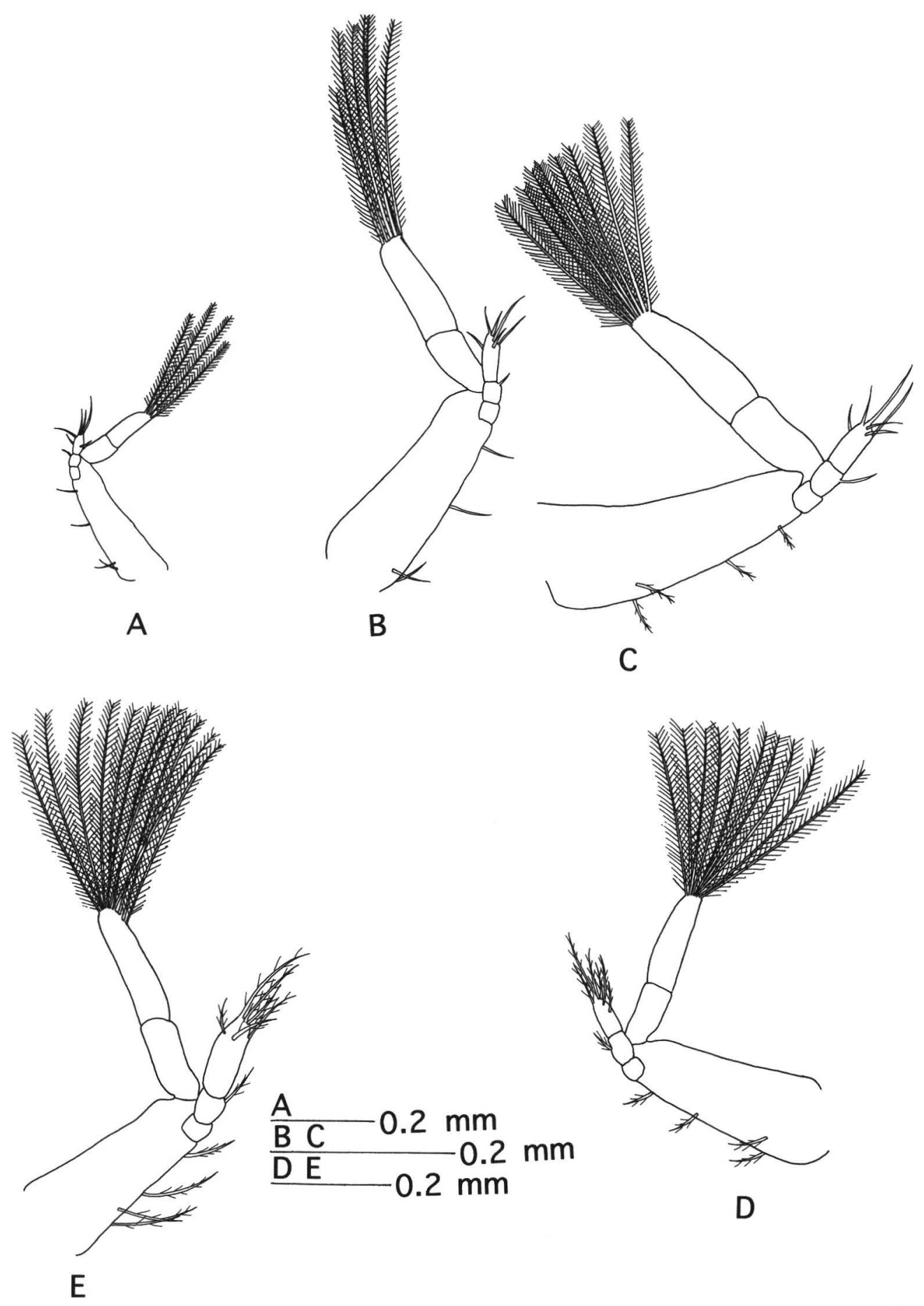

Fig. 9. Helice leachi Hess. Maxillipeds 2: A-E, zoea I-V. 


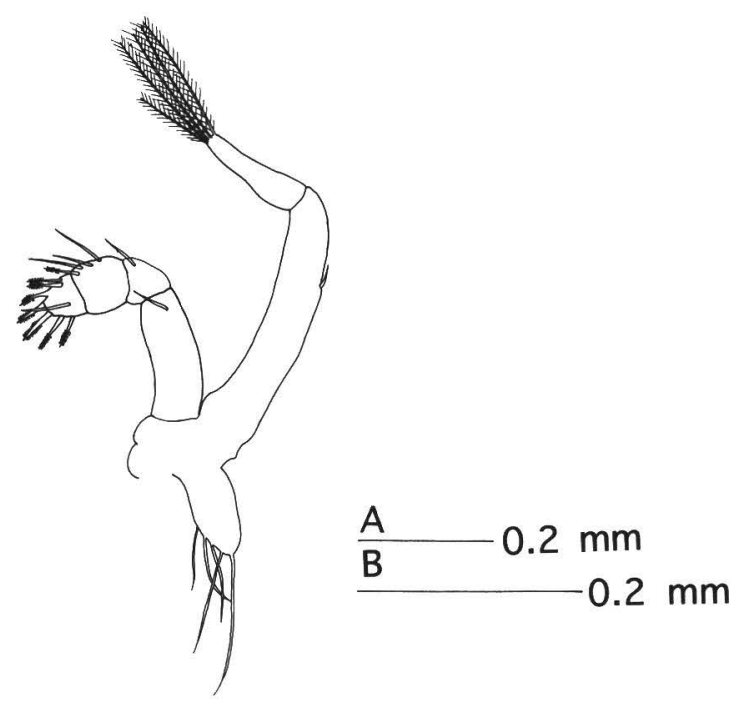

A

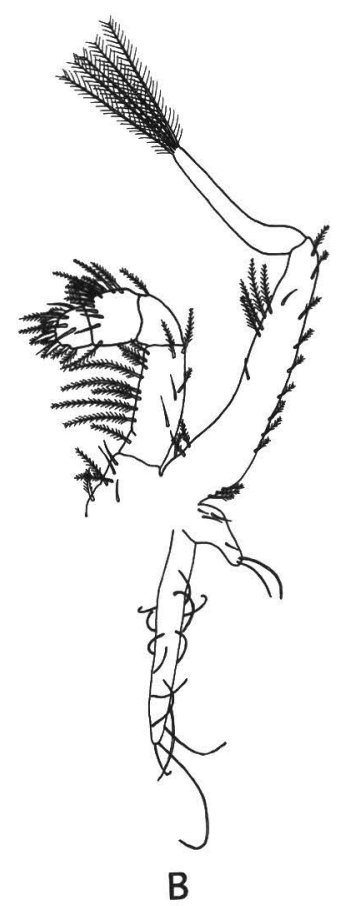

Fig. 10. Helice leachi Hess. Maxillipeds 2: A, megalopa; B, first crab.
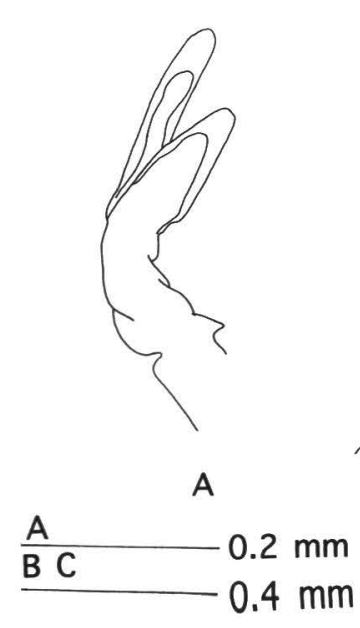

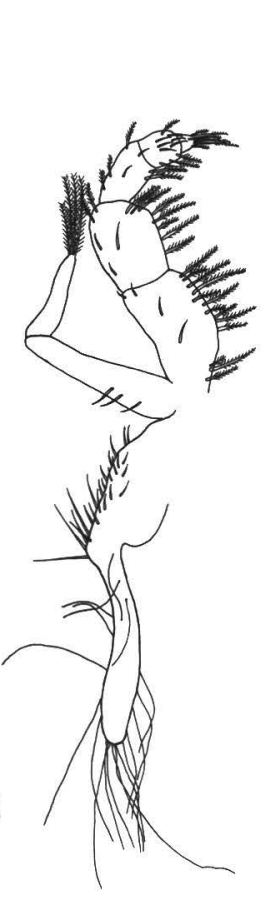

B

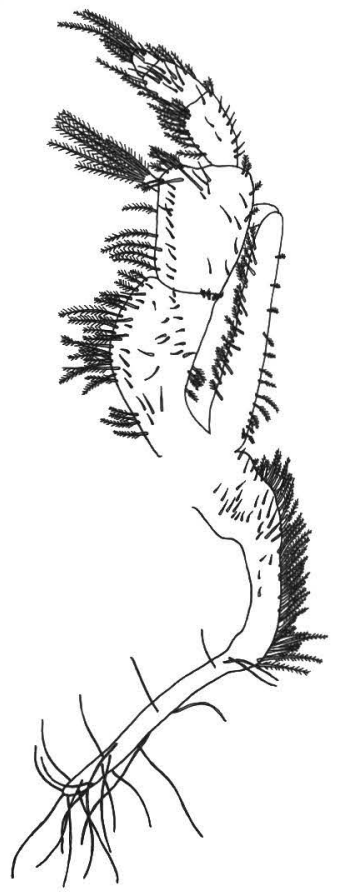

C

Fig. 11. Helice leachi Hess. Maxillipeds 3: A, zoea-V; B, megalopa; C, first crab. 
plumose natatory setae.

Maxilliped 2 (Fig. 9E): Exopod with 12 plumose natatory setae.

Maxilliped 3 (Fig. 11A): Simply bilobed and naked.

Pereiopods (Fig.14A ): Elongated and segmented.

Abdomen (Fig. 12F \& G): Well-developed, somite 6 with buds of biramous pleopods and uropods. Telson unchanged.

\section{MEgalopa}

Size: CL, $1.84 \mathrm{~mm}$; CW, $1.34 \mathrm{~mm}$.

Carapace (Fig. 1F): Quadrangular in dorsal view, with smooth dorsal surface; longer than broad. Eyes large and stalked.

Antennule (Fig. 2F): Enlarged base with 3 setae. Peduncle 2-segmented; basal segment with 4 setae; inner flagellum unsegmented, bearing 3 terminal plus 1 subterminal setae; outer flagellum with 8 aesthetascs and 3 setae.

Antenna (Fig. 3F): Peduncle 3-segmented, with 1, 1, 3 setae. Flagellum 7segmented, with 0, 0, 4, 1, 5, 2, 4 setae.

Mandible (Fig. 4F): Cutting edge almost straight ; palp 2-segmented, distal segment with 9 setae.

Maxillule (Fig. 5F): Unsegmented endopod bearing 7 simple setae. Basal endite with 24 hairy spines and 3 naked setae; coxal endite with 15 hairy spines and 7 naked setae.

Maxilla (Fig. 6F): Endopod with 3 lateral plumose setae; basal and coxal endites bilobed; basal endite with 10 setae on distal lobe and 7 setae on proximal lobe; coxal endite with 10 plumose setae on distal lobe and 18 on proximal lobe; scaphognathite fringed with 69 plumose setae and 7 on blade surface.

Maxilliped 1 (Fig. 8A): Endopod with 2 lateral setae; basal and coxal endites with 12 and 11 setae, respectively; exopod 2segmented, with 2, 4 plumose setae; epipod with 9 long simple setae.

Maxilliped 2 (Fig. 10A): Endopod 4segmented, with 1, 1, 4, 8 setae; 2 -seg- mented exopod, proximal segment with 1 seta, distal segment with 5 terminal plumose setae; epipod with 5 naked setae of moderate length.

Maxilliped 3 (Fig. 11B): Endopod 5segmented, with setal formula 17, 13, 7, 10, 6; exopod 2-segmented, with setation of 3,4 ; coxa and basis fused, with 22 setae; epipod with 5 medium-sized setae and 14 long setae marginally.

Pereiopods (Fig. 14B-F): Well-developed; chelipeds subequal, toothless on cutting edge; pereiopods 2-4 similar; dactyli of pereiopods 2-4 tapering, slightly curved, armed with several spines on both surfaces; pereiopod 5 with dactyli terminally bearing 3 long curved serrate setae.

Abdomen and telson (Fig. 13A-F): Six somites; posterolateral margins of each somite rounded; somite 1 with 4 lateral setae on each side; somites 2-6 with several setae on posterolateral and posterodorsal margins. Functional pleopods present on somites 2-4; endopod with 3 minute hooks; exopods of pleopods $1,2,3$, 4 bearing 19, 20, 22 and 20 plumose natatory setae, respectively. Uropods uniramous, bearing 13 natatory plumose setae. Telson semicircular, with 1 pair of setae on posteodorsal region; longer than somite 6 .

\section{FIRST CRAB}

Size: CL, $1.84 \mathrm{~mm}$; CW, $1.72 \mathrm{~mm}$.

Carapace (Fig. 1G): Carapace as long as broad. Anterior half of lateral margin with 3 teeth. Front less than half of greatest width of carapace. Antenna situated outside orbit. Eyes large and movable.

Antennule (Fig. 2G): Almost as in megalopa. Inner flagellum 2-segmented, distal segment bearing 4 setae.

Antenna (Fig. 3G): Peduncle 4-segmented, with $3,14,10,3$ setae; flagellum 7-segmented, with 0, 0, 0, 3, 2, 4, 6 setae.

Mandible (Fig. 4G): Cutting edge sharp; palp 3-segmented, with $3,4,18$ setae.

Maxillule (Fig. 5G): Endopod unseg- 


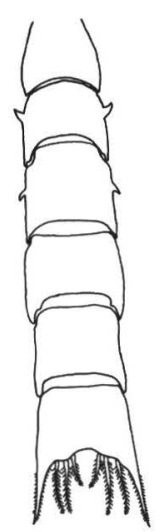

A

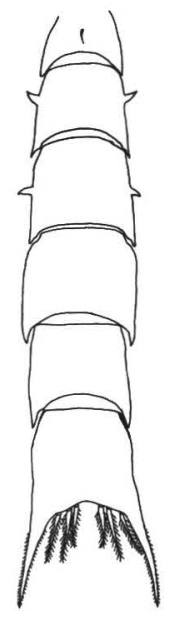

B

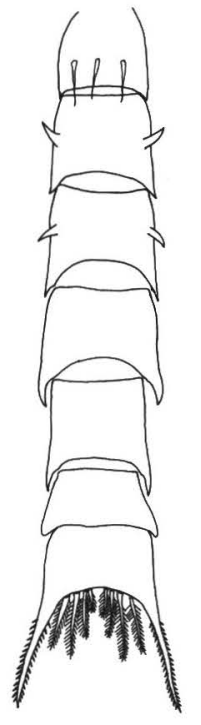

C

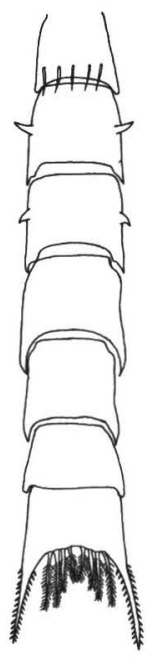

D

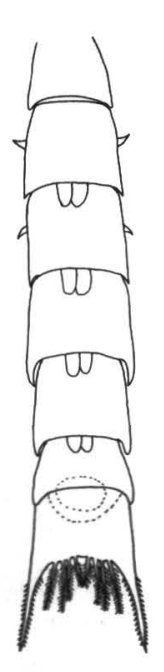

$E$

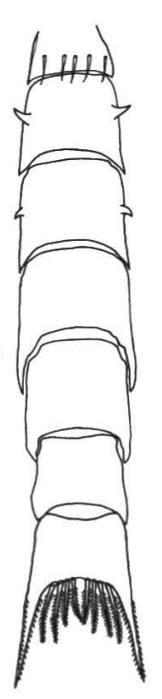

$\mathrm{F}$
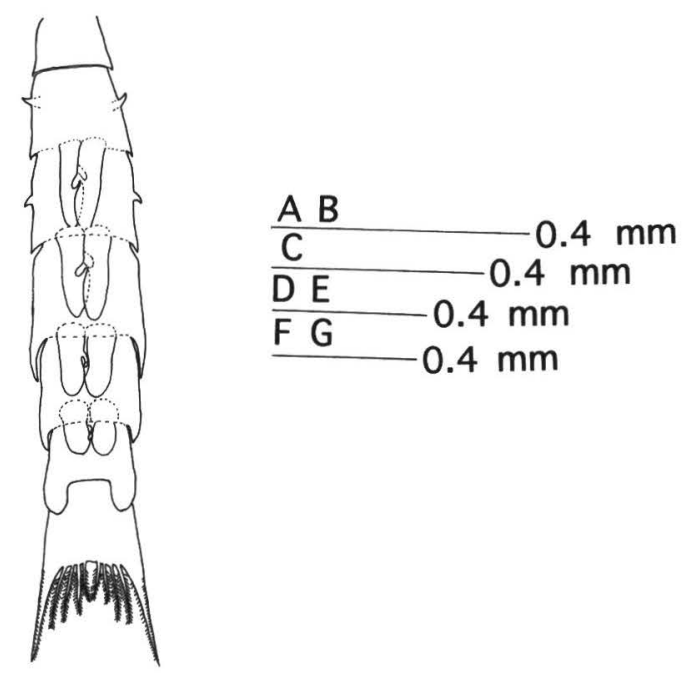

Fig. 12. Helice leachi Hess. Abdomen: A-D \& F, dorsal view of zoea I-V; E \& G, ventral view of zoea IV-V. 


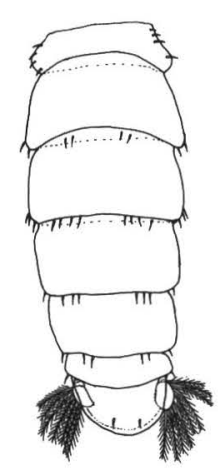

A

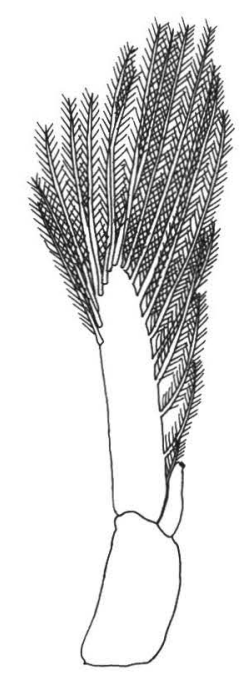

B

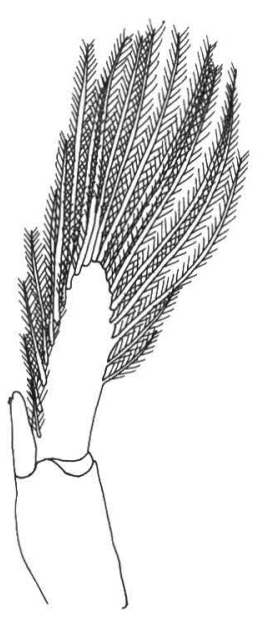

C

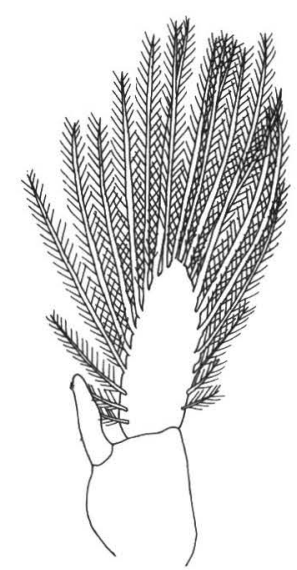

D

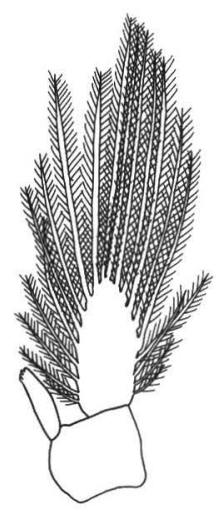

E

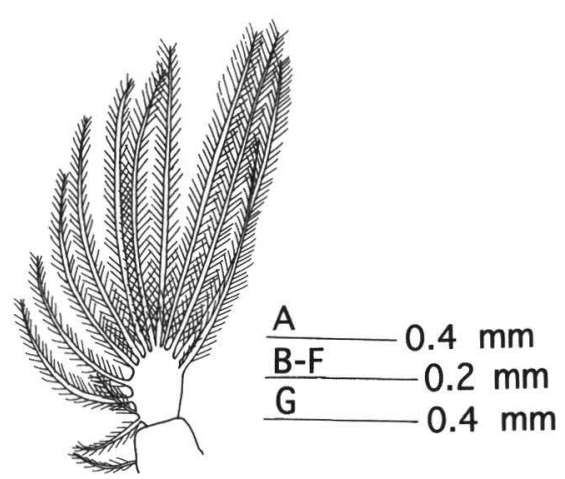

F

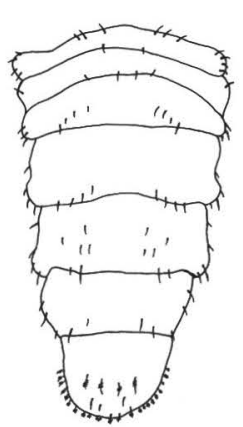

G

Fig. 13. Helice leachi Hess. Abdomen: A, megalopa; B-E, pleopods; f, uropod; G, first crab.

mented, Y-shaped; bearing 4 plumose and 3 simple setae on surface and margin. Basal endite with 22 hairy spines and 6 setae; coxal endite with 18 hairy spines and 18 setae.
Maxilla (Fig. 6G): Endopod with 1 simple lateral setae. Basal endite with 14 setae on distal lobe and 12 on proximal lobe; coxal endite with 13 setae on distal lobe and 25 on proximal lobe; scapho- 


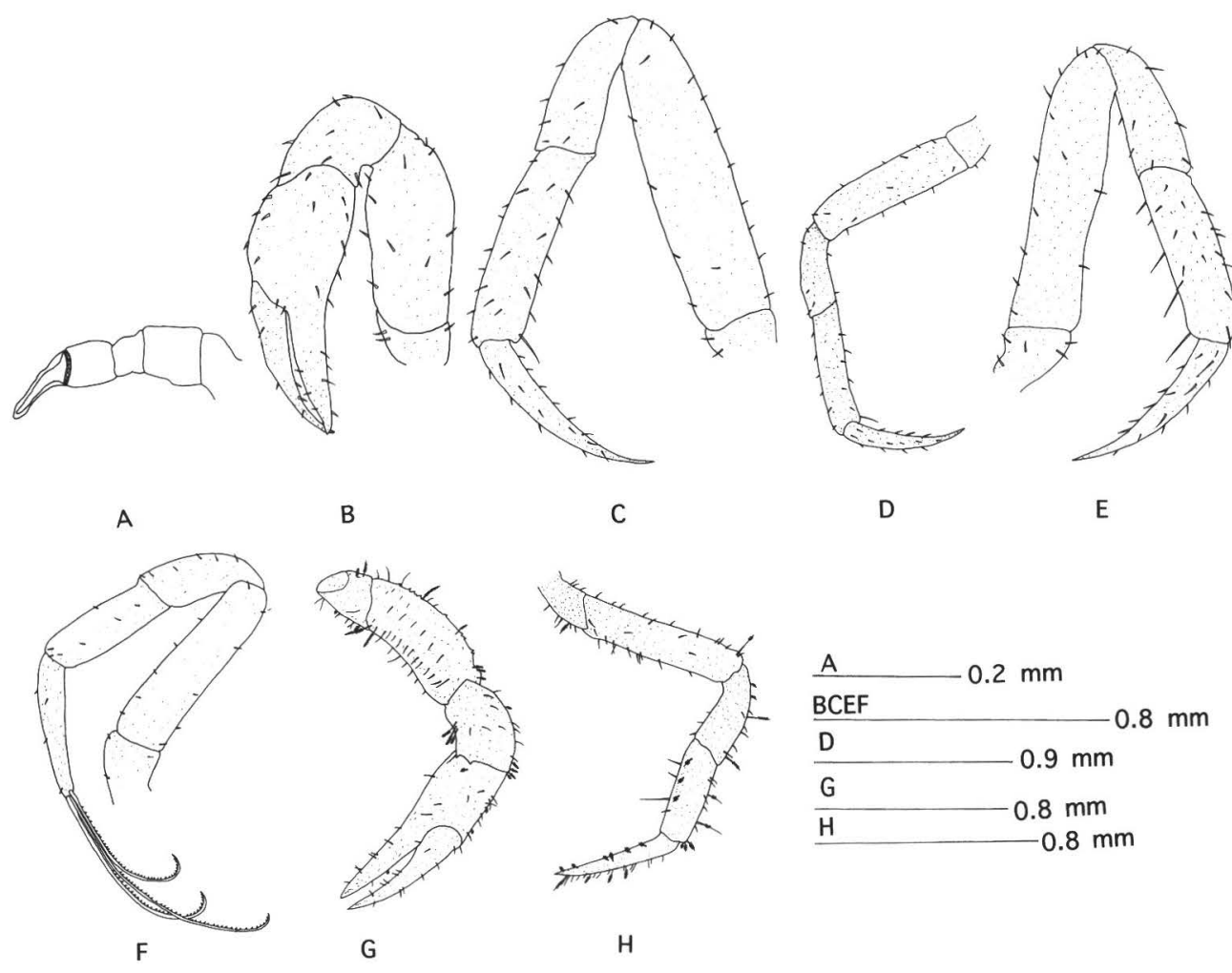

Fig. 14. Helice leachi Hess. Pereiopods: A, 1st of zoea-V; B-F, 1, 2, 3, 4 \& 5th of megalopa; G-H, 1 st \& 5 th of first crab.

gnathite with 89 hairy setae on margin and 12 simple setae on blade surface.

Maxilliped 1 (Fig. 8B): Endopod bilobed, with several setae on margin and surface; setation of both endites more complex than in megalopa; 2-segmented exopod with 3, 4 plumose setae; elongated epipod with 24 long setae and 1 short seta distally.

Maxilliped 2 (Fig. 10B): Endopod 4segmented, with $14,1,13,12$ setae; exopod 2-segmented, proximal segment with 21 setae, distal segment with 5 terminal plumose setae; bilobed epipod with 6, 14 naked setae.

Maxilliped 3 (Fig. 11C): Endopod wider than in megalopa. Exopod and epipod similar to those of megalopa, but setation of endopod, exopod and epipod more complex than in megalopa.

Pereiopods (Fig. 14G-H): Chelipeds equal in size, with numerous setae; pereiopods 2-4 similar; dactylus pointed, nearly equal to propodus in length; third pereiopod largest, fifth one smallest.

Abdomen and telson (Fig. 13G): Six somites; each somite with several setae on dorsal surface and lateral margins. Posterior margin of telson rounded, with numerous setae. Pleopods and uropods degenerated.

\section{Discussion}

The first and second zoeae of $H$. leachi were described by Baba et al. (1984), and they suggested that there might be five zoeal stages. It was also suggested that 
Table 1. Morphological differences among the larvae of Helice leachi, H. japonica and H. tridens.

\begin{tabular}{|c|c|c|c|}
\hline Stage and character & H. leachi & H. japonica* ${ }^{*}$ & H. tridens ${ }^{*}$ \\
\hline \multicolumn{4}{|l|}{ Zoea I-V } \\
\hline Lateral spine on carapae & absent & present & present \\
\hline \multicolumn{4}{|l|}{ Zoea I } \\
\hline \multicolumn{4}{|l|}{ Antennule } \\
\hline Aesthetascs and setae & 3,1 & 3,1 & 2,1 \\
\hline \multicolumn{4}{|l|}{ Maxillule } \\
\hline Setation of coxal and basal endites & 4,5 & 4,5 & 4,5 \\
\hline \multicolumn{4}{|l|}{ Zoea II } \\
\hline \multicolumn{4}{|l|}{ Antennule } \\
\hline Aesthetases and setae & 4,0 & 4,1 & 3,1 \\
\hline Setae on abdominal somite 1 & 1 & ? & $?$ \\
\hline \multicolumn{4}{|l|}{ Zoea III } \\
\hline \multicolumn{4}{|l|}{ Antennule } \\
\hline Aesthetascs and setae & 4,0 & 4,1 & 4,0 \\
\hline \multicolumn{4}{|l|}{ Maxillule } \\
\hline Setation of coxal and basal endites & 6,8 & 5,8 & 5,7 \\
\hline \multicolumn{4}{|l|}{ Zoea IV } \\
\hline \multicolumn{4}{|l|}{ Antennule } \\
\hline Aesthetascs and setae & 6,0 & 4,1 & 4,1 \\
\hline \multicolumn{4}{|l|}{ Maxillule } \\
\hline Setation of coxal and basal endites & 7,12 & 6,11 & 6,12 \\
\hline \multicolumn{4}{|l|}{ Maxilla } \\
\hline Setation of coxal and basal endites & 7,11 & 9,10 & 8,10 \\
\hline Setation of scaphognathite & 26 & 22 & 21 \\
\hline \multicolumn{4}{|l|}{$\begin{array}{l}\text { Zoea V } \\
\text { Telson }\end{array}$} \\
\hline \multicolumn{4}{|l|}{ Telson } \\
\hline Posterior marginal setae & 4 pairs & 5 pairs & 5 pairs \\
\hline \multicolumn{4}{|l|}{ Antennule } \\
\hline Aesthetascs and setae & 8,0 & 9,0 & 5,1 \\
\hline \multicolumn{4}{|l|}{ Maxillule } \\
\hline Setation of coxal and basal endites & 8,16 & 8,14 & 8,14 \\
\hline \multicolumn{4}{|l|}{ Maxilla } \\
\hline Setation of coxal and basal endites & 10,16 & 9,14 & 8,16 \\
\hline Setation of scaphognathite & 35 & 28 & 30 \\
\hline \multicolumn{4}{|l|}{ Maxilliped 1} \\
\hline Natatory setae of exopod & 11 & 12 & 12 \\
\hline \multicolumn{4}{|l|}{ Megalopa } \\
\hline \multicolumn{4}{|l|}{ Maxillule } \\
\hline Setation of endopod & 7 & 4 & 5 \\
\hline Setation of coxal and basal endites & 22,27 & 11,19 & 13,18 \\
\hline \multicolumn{4}{|l|}{ Maxilla } \\
\hline Setation of endopod & 3 & 2 & 2 \\
\hline Setation of coxal and basal endites & $7+10,18+10$ & $6+11,11+3$ & $8+11,18$ \\
\hline Setation of scaphognathite & & & \\
\hline (on margin and blade surface) & 69,7 & 58,0 & 51,0 \\
\hline Maxilliped 2 & & & \\
\hline Setation of exopod & 1,5 & 5 terminal & 4 terminal \\
\hline Maxilliped 3 & & & \\
\hline Setation of exopod & 3,4 & 4 terminal & 5 terminal \\
\hline
\end{tabular}

*Baba \& Moriyama (1972) 
the lateral carapace spine might be absent in all zoeal stages. These are now confirmed by our present study.

In this paper, the larval characters of $H$. leachi obtained by laboratory rearing are compared with those of $H$. tridens and $H$. japonica reported by Baba \& Moriyama (1972) (Table 1).

The zoeae of $H$. leachi are readily distinguished from those of $H$. tridens and $H$. japonica by the absence of carapace lateral spines and the presence of simple setae on the dorsal spine. The lateral spine on the fourth abdominal somite, as seen in the first zoea of $H$. tridens, is absent in both $H$. leach $i$ and $H$. japonica. The posterior margin of the telson in the fifth zoeal stage of $H$. leachi bears four pairs of plumose setae, instead of five pairs as in the other two species.

The first and second zoeae of $H$. leachi examined here agree well with the description by Baba et al. (1984), only except for a seta on the dorsal surface of the first abdominal somite, which is present in our specimens of the second zoea, but absent in the Baba et al. specimens. The presence of setae on this somite seems to be consistent in the second to fifth zoeae (Fig. 12). It seems possible that Baba et al. might have overlooked this seta.

In the megalopal stage, no distinct differences were noted among the species of Helice, other than the setation of appendages, which, seems to be subject to individual variation. The posterior margin of the telson bears three setae in $H$. tridens, four in H. japonica, and none in $H$. leachi. A slight difference is also found in the setation of exopods of the maxillipeds 1-3; it is 4-5-4 in both $H$. leachi and $H$. japonica, 4-4-5 in H. tridens.

The first crab stage is known only in $H$. japonica (see Baba et al., 1984). Helice leachi and $H$. japonica can be separated by the following differences: 1) the lateral margin of the carapace bears three distinct teeth in $H$. leachi, with four in $H$. japonica; 2) the inner flagellum of the antennule is two-segmented, bearing three terminal plus one subterminal setae on the distal segment in $H$. leachi, while in $H$. japonica, it is unsegmented and bears two terminal setae; and 3) the mandibular palp is three-segmented in $H$. leachi, but two-segmented in $H$. japonica.

\section{Acknowledgments}

We would like to thank Dr. Robert van Woesik, of the University of the Ryukyus, for his critical reading of the manuscript, Dr. S. Y. Hong of the National Fisheries University of Pusan, for reviewing the manuscript, and Mr. Arata Kawakami of the University of the Ryukyus, for his assistance.

\section{Literature Cited}

Baba, K., Fukuda, Y., \& Nakasone, Y., 1984. Zoeal morphology of the sesarmine crab, Helice leachi (Hess) (Crustacea: Decapoda: Brachyura). Memoirs of the Faculty of Education, Kumamoto University, 33: 410.

—, \& Moriyama, M., 1972. Larval development of Helice tridens wuana Rathbun Memoirs of the Faculty of Education, Kumamoto University, 21 (1): 49-68.

Dai, A. Y,. \& Yang, S. L., 1991. Crabs of the China Seas. China Ocean Press, Beijing, 682 pp., with 368 figures.

Sakai, T., 1976. Crabs of Japan and the Adjacent Seas. (In 3 vols., 1 : English text, xxix + 773 pp., figs. 1-379; 2: plate volume, 16 pp., pls.1-251; 3: Japanese text, 461 pp., figs.1, 2. Kodansha Ltd. Tokyo)

Address: Department of the Marine Sciences, University of the Ryukyus, 1 senbaru, Nishihara-cho, Okinawa 903-01, Japan.

E-mail: (SS) shokita@ sci.u-ryukyu.ac.jp 